
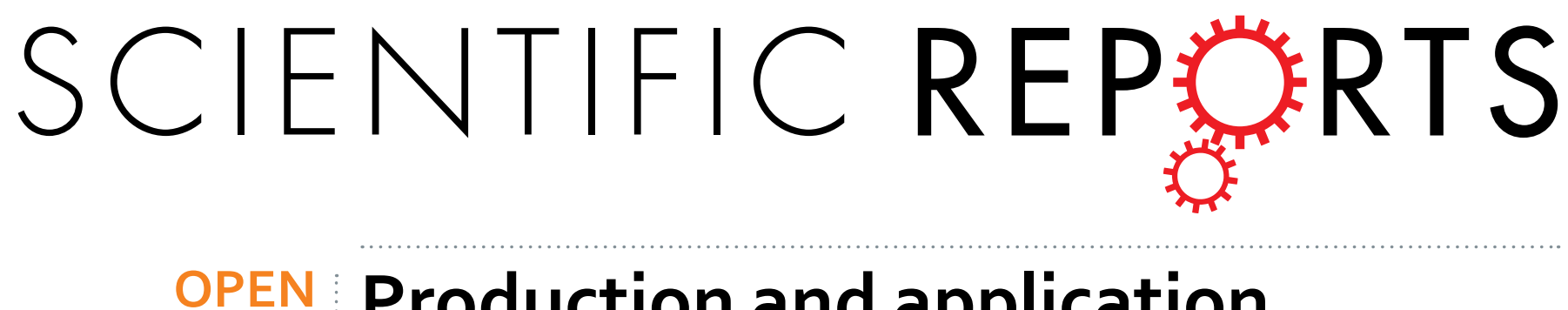

\title{
Production and application of polyclonal and monoclonal antibodies against Spiroplasma
}

Received: 29 June 2015

Accepted: 06 November 2015

Published: 07 December 2015

\section{eriocheiris}

\author{
Ying Zhang ${ }^{1}$, Haixun Bao ${ }^{1}$, Fengqin Miao ${ }^{1}$, Yaqin Peng ${ }^{1}$, Yuqing Shen ${ }^{1}$, Wei Gu ${ }^{2}$ \\ Qingguo Meng ${ }^{2}$, Wen Wang ${ }^{2}$ \& Jianqiong Zhang ${ }^{1}$
}

A new species of spiroplasma, Spiroplasma eriocheiris (S. eriocheiris), was identified as a lethal pathogen of tremor disease (TD) in Chinese mitten crab recently. In order to acquire appropriate biological and diagnostic tools for characterizing this newly discovered pathogen, 5 monoclonal antibodies (mAbs) and a polyclonal antibody (pAb) against S. eriocheiris were produced. Among the $m A b s, 6 F 5,7 C 8$ and $12 \mathrm{H} 5$ lead to the deformation of $S$. eriocheiris. A peptide sequence, YMRDMOSGLPRY was identified as a mimic motif of MreB that is the cell shape determining protein of $S$. eriocheiris interacting with 3 mAbs. Furthermore, a double antibody sandwich enzyme-linked immunosorbent assay (DAS-ELISA) for detection of $S$. eriocheiris was established using the $\mathrm{mAb}$ and $\mathrm{pAb}$ we prepared. It detected as low as $0.1 \mu \mathrm{g} / \mathrm{mL}$ of $S$. eriocheiris. No cross-reaction was observed with three other common bacteria (Pseudomonas aeruginosa, Escherichia coli, and Bacillus subtilis) and the hemolymph samples of healthy Eriocheir sinensis. Collectively, our results indicated that the mAbs and pAb we prepared could be used in the analysis of $S$. eriocheiris membrane proteins mimotope and development of a diagnostic kit for S. eriocheiris infections.

The Chinese mitten crab, Eriocheir sinensis, is an economically important species cultured in China. Tremor disease (TD) is one of the most serious epizootics of the crab that adversely affect harvests in recent years. In 2002, it was the first time that a pathogenic spiroplasma in a crustacean was detected; and subsequently it was identified as a causative agent of TD in $2004^{1}$. In 2010, it was given the name Spiroplasma eriocheiris ${ }^{1}$. S. eriocheiris infects not only the crab but also three other freshwater crustaceans: pacific white shrimp (Litopenaeus vannamei), crayfish (Procambarus clarkii) and prawn (Macrobrachium rosenbergii and Macrobrachium nipponense), leading to a massive death ${ }^{2}$.

Spiroplasmas are wall-less, helical, motile prokaryotes, which were most often found in association with insects and ticks. At a much lower frequency, they have also been isolated from plants ${ }^{3}$. Recent isolations from crustaceans are beginning to widen our understanding of the host range. As a member of cell-wall-free mollicutes, its membrane proteins are of primary importance in adherence, invasion, and interaction with the host, and they may also display structural, transport, or enzymatic functions ${ }^{4}$. To date, three types of $S$. eriocheiris surface proteins, SLP25 (Spiralin-like protein), SLP31 and ALP41 (adhesin-like protein), have been cloned and expressed ${ }^{4-6}$. In our previous study, we generated and characterized the first $\mathrm{mAb}(6 \mathrm{H} 7)$ against $S$. eriocheiris, and using this $\mathrm{mAb}$, we identified a motif of ALP41 $1^{7}$. The analysis of more mimotopes of $S$. eriocheiris membrane proteins and potential roles of them will be helpful in further research on characterization of S. eriocheiris and its pathogenesis.

There is no specific treatment or vaccine for TD, so rapid and accurate diagnosis during the early course is essential to control this disease. S. eriocheiris infection can be detected by several molecular and/or immunological techniques ${ }^{8}$. However, most of them require special equipment and expensive reagents except the enzyme-linked immunosorbent assay (ELISA) method, which has been used for many years as a field diagnostics. An indirect

${ }^{1}$ Key Laboratory of Developmental Genes and Human Disease, Ministry of Education, Department of Microbiology and Immunology, Medical School, Southeast University, 87 Dingjiaqiao Road, Nanjing 210009, China. ${ }^{2}$ Jiangsu Key Laboratory for Biodiversity \& Biotechnology and Jiangsu Key Laboratory for Aquatic Crustacean Diseases, College of Life Sciences, Nanjing Normal University, 1 Wenyuan Road, Nanjing 210023, China. Correspondence and requests for materials should be addressed to J.Z. (email: zhjq@seu.edu.cn) 

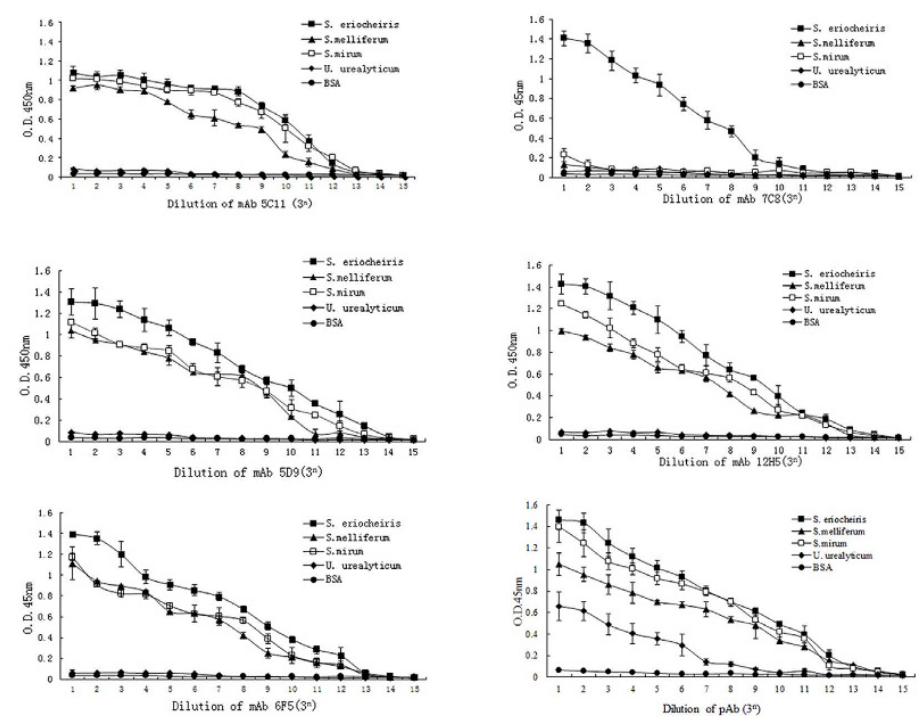
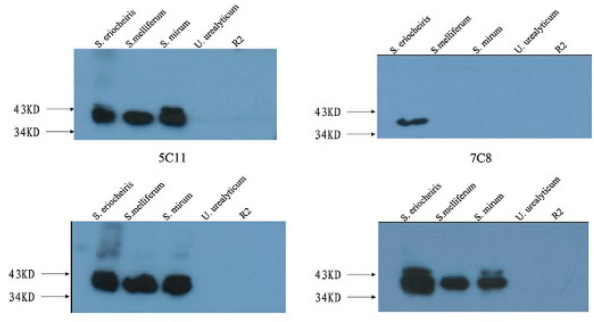

$12 \mathrm{HS}$
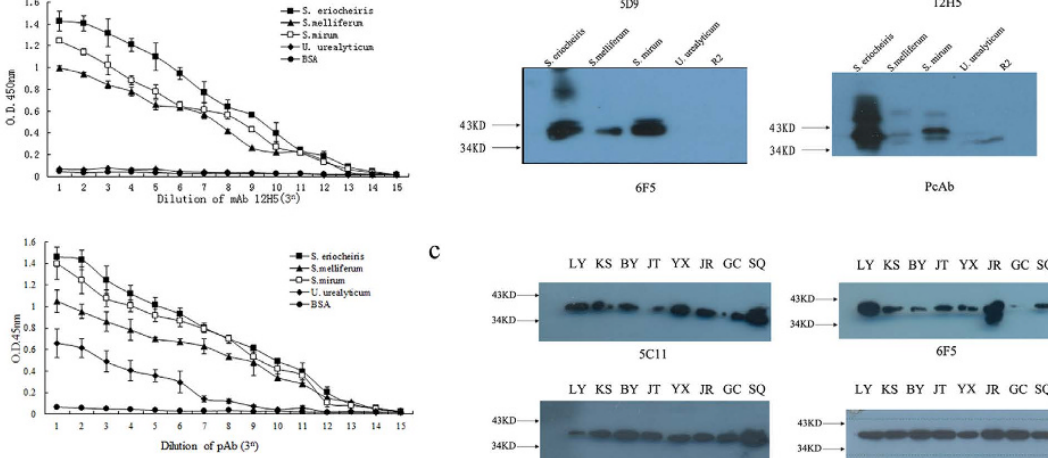

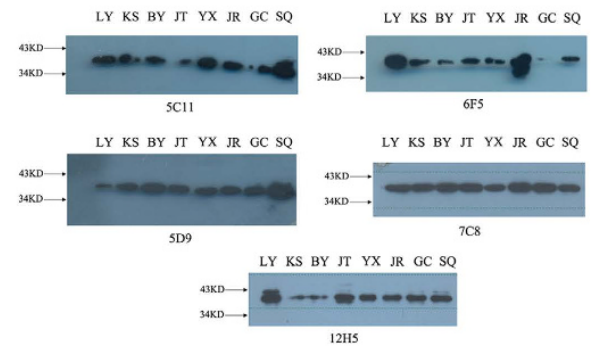

Figure 1. (a) Reactions of the mAbs 5C11, 5D9, 6F5, 12H5, 7C8 and pAb to different species of Spiroplasmas or U. urealyticum by indirect ELISA assay. The wells were coated with $300 \mathrm{ng}$ whole cell lysates of S. eriocheiris $(\boldsymbol{\square})$, S. melliferum $(\boldsymbol{\Delta})$, S. mirum $(\square)$ and U. urealyticum $(\diamond)$. BSA $(\bullet)$ was used as control. The mAbs and pAb initially adjusted to $1 \mathrm{mg} \mathrm{mL}^{-1}$ was tested in fifteen three-fold dilutions. First dilution $3^{1}(\mathrm{n}=1)$ and last $3^{15}$ $(n=15)$. Optical density was measured at $450 \mathrm{~nm}$. The experiment was repeated three times, and the results are presented as mean $\pm \mathrm{SD}$. (b) Reactions of the $\mathrm{mAbs}$ and $\mathrm{pAb}$ with the whole cell lysates of S. eriocheiris, S. melliferum, S. mirum, U. urealyticum, and culture medium of the Spiroplasmas (R2) used as control.

(c) Reactions of the mAbs with S. eriocheiris strains from eight areas by Western blot assay. S. eriocheiris strains of different areas (Lane 1: Liyang; Lane 2: Kunshan; Lane 3: Baoying; Lane 4: Jintan; Lane 5: Yixing; Lane 6: Jurong; Lane 7: Gaochun; Lane 8: Suqian).

ELISA using pAb prepared for the rapid detection of S. eriocheiris was developed, but it is time-consuming and the sensitivity and specificity needs to be improved ${ }^{8}$.

The main objective of our study was to generate and characterize more mAbs and pAb against S. eriocheiris. These antibodies were used to analyse mimotopes of its membrane proteins and to develop DAS-ELISA, enhancing the ability to detect and confirm suspected cases of S. eriocheiris infection. This in turn may reduce TD mortality and direct strategies for controlling infection.

\section{Results}

Characterization of the pAb and mAbs 5C11, 5D9, 6F5, 12H5, 7C8. Whole-cell S. eriocheiris and $S$. eriocheiris cells broken by ultrasonic homogenizer were used separately as Ag to produce mAbs. After the fusion of the host spleen cells with the myeloma cells, we found that the ratio of fusion from the former type of antigen was about $80 \%$, while that from the latter was $70 \%$. Indirect ELISA was done to screen for the hybridoma cells that could secrete $\mathrm{mAbs}$ capable of binding to $S$. eriocheiris. The cells that have strong ELISA reactivities with S. eriocheiris were subsequently subjected to cloning procedures. Five clones (5C11, 5D9, 6F5, $12 \mathrm{H} 5$ and 7C8) with higher titer, affinity, and good cell growth status were finally obtained for further characterization.

The titers (expressed as the reciprocal of the ascites or serum dilution) of the mAbs reached $3^{11}-3^{14}$, and that of pAb was $3^{14}$ as determined by indirect ELISA. Specificity analyses of the mAbs and pAb were done by indirect ELISA and Western blotting. The results of indirect ELISA assay showed that 7C8 reacted with S. eriocheiris when

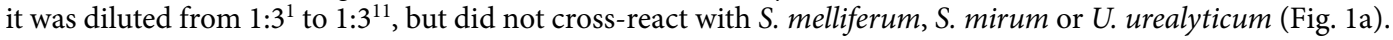
Moreover, the other four mAbs reacted with S. eriocheiris, S. melliferum and S. mirum, but not with U. urealyticum (Fig. 1a). The pAb reacted with all of the 4 members of Mollicutes, while not with the negative control (Fig. 1a). These results suggested that $\mathrm{mAb} 7 \mathrm{C} 8$ recognized a $S$. eriocheiris specific epitope, while the other four $\mathrm{mAbs}$ recognized an epitope common to all of the 3 spiroplasmas. The results were further confirmed by Western blot assay, which revealed that $\mathrm{mAb} 7 \mathrm{C} 8$ was capable of identifying the protein band (about $40 \mathrm{kDa}$ ) and is in good accordance with those of the other four mAbs (Fig.1b).

The light-chain isotypes of the $5 \mathrm{mAbs}(5 \mathrm{C} 11,5 \mathrm{D} 9,6 \mathrm{~F} 5,12 \mathrm{H} 5$ and $7 \mathrm{C} 8)$ were $\kappa$, while the heavy-chain isotypes were not the same by detection using mouse $\mathrm{mAb}$ isotyping test kit. Affinity constant $\left(\mathrm{K}_{\mathrm{aff}}\right)$ of the mAbs was measured by indirect ELISA. The results are summarized in Table 1 . As shown, these mAbs exhibited higher affinity for S. eriocheiris. The $\mathrm{K}_{\mathrm{aff}}$ ranged between $7.04 \times 10^{6}$ and $6.21 \times 10^{8}$. 


\begin{tabular}{|c|c|c|c|c|}
\hline Clones number & Isotype & Affinity constant $\left(\mathrm{M}^{-1}\right)$ & Titre & Specificities \\
\hline \multirow[t]{2}{*}{$5 \mathrm{C} 11$} & $\mathrm{IgG} 1 / \kappa$ & $1.37 \times 10^{7}$ & $3^{12}$ & S. eriocheiris + , S. melliferum + , \\
\hline & & & & S. mirum,+ U. urealyticum - \\
\hline \multirow[t]{2}{*}{ 5D9 } & $\operatorname{IgG1} / \kappa$ & $7.04 \times 10^{6}$ & $3^{13}$ & S. eriocheiris + , S. melliferum + , \\
\hline & & & & S. mirum,+ U. urealyticum - \\
\hline \multirow[t]{2}{*}{$6 \mathrm{F5}$} & $\mathrm{IgG} 1 / \mathrm{\kappa}$ & $6.21 \times 10^{8}$ & $3^{13}$ & S. eriocheiris + , S. melliferum + , \\
\hline & & & & S. mirum + , U. urealyticum - \\
\hline \multirow[t]{2}{*}{$7 \mathrm{C} 8$} & IgG2a/ $\kappa$ & $1.19 \times 10^{8}$ & $3^{11}$ & S. eriocheiris,+ S. melliferum - , \\
\hline & & & & S. mirum -, U. urealyticum - \\
\hline \multirow[t]{2}{*}{$12 \mathrm{H} 5$} & $\mathrm{IgG} 1 / \kappa$ & $1.66 \times 10^{8}$ & $3^{14}$ & S. eriocheiris + , S. melliferum + , \\
\hline & & & & S. mirum,$+ U$. urealyticum - \\
\hline
\end{tabular}

Table 1. Identification of subclasses, titers and affinity constants for mAbs. The mark ' +' or '-' in specificities indicates reacted with or not reacted with.

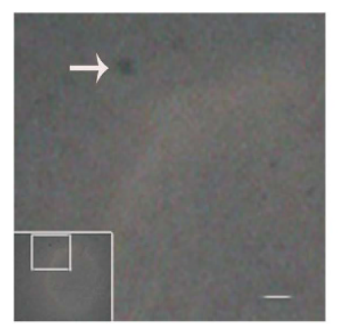

$6 \mathrm{~F} 5$

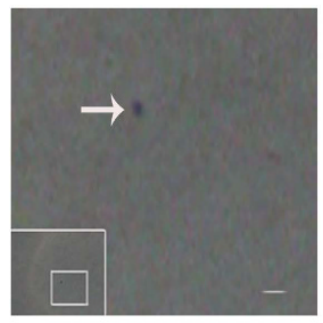

$12 \mathrm{H} 5$

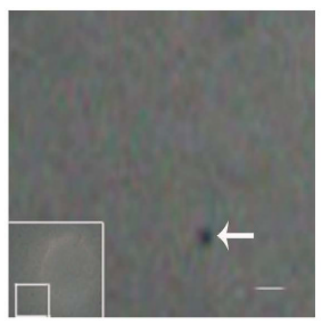

$7 \mathrm{C} 8$

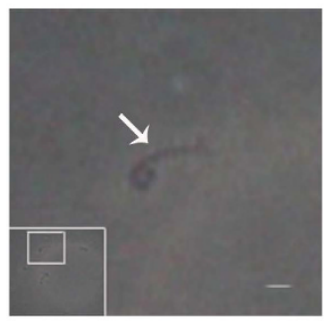

$\mathrm{R} 2$

Figure 2. Effects of mAbs 6F5, 7C8, $12 \mathrm{H} 5$ on the shapes of $S$. eriocheiris. Oil immersion lens micrographs of samples of $S$. eriocheiris cultures in the logarithmic phase of growth added with $6 \mathrm{~F} 5,7 \mathrm{C} 8,12 \mathrm{H} 5$ or R2, showing round $(6 \mathrm{~F} 5,7 \mathrm{C} 8,12 \mathrm{H} 5)$ and helical (R2) structures. Arrows indicate the intact and deformed cells on images.

Above-mentioned data showed that a strong specific response could be elicited by the $\mathrm{mAb} 7 \mathrm{C} 8$, and it is relatively specific for the other four mAbs. In order to verify if the motifs recognized by the mAbs were shared by the strains from different areas in Jiangsu province, S. eriocheiris strains isolated from E. sinensis of TD in 8 different areas in Jiangsu province were detected with the $5 \mathrm{mAbs}$ by Western blot analysis. The results showed that the mAbs reacted with all of the S. eriocheiris strains collected from the above areas (Liyang, Kunshan, Baoying, Jintan, Yixing, Jurong, Ggaochun and Suqian), implying that the binding epitopes of these mAbs were conserved among these strains (Fig. 1c).

Effects of the mAbs on the biological characteristics of $S$. eriocheiris. A dark field microscope was used to observe the samples for helicity. Most S. eriocheiris in the presence of mAb 5D9, 5C11 or absence of any $\mathrm{mAb}$ exhibited initial helicity (Fig. $2 \mathrm{R} 2$ ). While mAb 6F5, $7 \mathrm{C} 8$ or $12 \mathrm{H} 5$ deformed $20 \%-30 \%$ of S. eriocheiris, showing round structures (Fig. 2 6F5, 7C8, 12H5).

On R2 agar, S. eriocheiris produced small yellow colonies after $17-25$ days of incubation at $30^{\circ} \mathrm{C}$, and there were not any red zones of inhibition of $S$. eriocheiris growth surrounding the disks saturated with the mAbs or R2 medium. This means the mAbs we tested did not inhibit the growth of S. eriocheiris.

There was simultaneously yellowing in S. eriocheiris suspension added with various dilutions of Abs compared with the control. This means the mAbs we tested did not inhibit the metabolism of S. eriocheiris.

Screening of phage display peptide libraries and characterization of recombinant phages. Analysis of peptide segments displayed on the surface of phage is a useful method to identify partners of the known proteins ${ }^{9,10}$. To investigate the binding motif of mAbs 6F5, 7C8 or $12 \mathrm{H} 5$ which deformed $S$. eriocheiris, the Ph.D.-12 libraries were screened with the purified mAbs. The yield rate increased significantly 


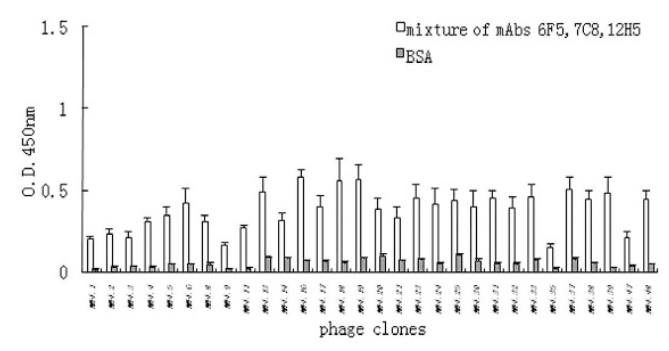

b

\begin{tabular}{cl}
\hline Bacterial or clone name & \multicolumn{1}{c}{ Amino acid sequence } \\
\hline & 242 \\
Wreb of S.eriocheiris & $\downarrow$ \\
Mreb of S.mirum & Y G R D V V S G L P R E \\
NM4.32, NM4.38 phage clones & Y G R D V V S G L P R E \\
& Y M R D M Q S G L P R Y \\
& $* \ldots * \ldots * * * *$. \\
\hline
\end{tabular}

c

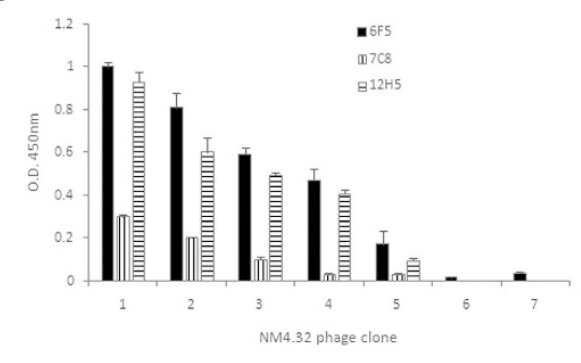

d

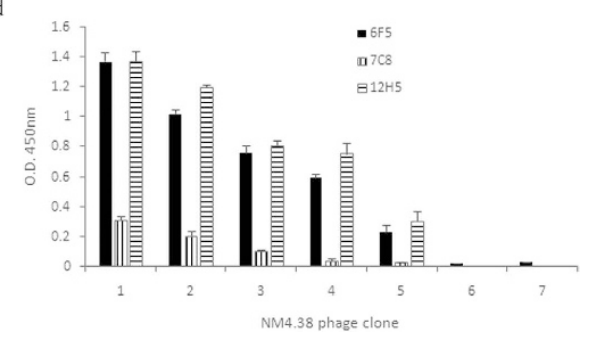

Figure 3. (a) Binding of different phages to the mAbs $6 \mathrm{~F} 5,7 \mathrm{C} 8$ and $12 \mathrm{H} 5$ detected by indirect ELISA. (b) Amino acid sequence comparisons between pep-NM4.32, NM4.38 and the related region of cell shape determining protein (Mreb) of S. eriocheiris and S. mirum using CLUSTAL W ver.3.1. The mark, 'asterisk' or 'dot', placed in the amino acid sequence indicates identical or different residues, respectively. (c,d) 6F5, 7C8 and $12 \mathrm{H} 5$ 's binding to NM4.32 or NM4.38 phage clone. ELISA was performed using plates coated with 6F5, 7C8 or $12 \mathrm{H} 5$, in the presence of NM4.32 or NM4.38 phage clone of serial dilutions. The binding of phage clone to the $\mathrm{mAbs}$ was detected by a HRP-conjugated anti-M13 mAb. BSA or unrelated mAb was also coated in the presence of NM4.32 or NM4.38 phage clone $\left(2.2 \times 10^{11}\right.$ virions/well) as a negative control.

from the first to the fourth round of biopanning $\left(1.63 \times 10^{-6}, 8.63 \times 10^{-4}, 3.16 \times 10^{-3}\right.$, and $2.29 \times 10^{-2}$, respectively), suggesting that high-affinity-binding peptides to the mAbs were significantly enriched during the screening procedure.

Among the 48 individual clones selected from biopanning, 30 clones were successfully sequenced. The deduced amino acid sequences of the corresponding inserts revealed 9 sequences. Interestingly, we found all these 30 clones showed higher signals in the phage ELISA binding assay (Fig. 3a). Among them, the amino acid sequence of pep-NM4.32 and NM4.38 was highly homologous to 242-253 amino acids of cell shape determining protein (Mreb1 and MreB4) from S. eriocheiris and S. mirum (Fig. 3b). These two clones were chosen for further analysis. Both NM4.32 and NM4.38 exhibited a significant, dose-dependent binding to 6F5, 7C8 and 12H5, even with $0.9 \times 10^{9}$ virions per well, while not binding to the irrelevant murine mAb (Fig. $3 \mathrm{c}, \mathrm{d}$ ). These results demonstrated that the residues (YMRDMQSGLPRY) contained a binding site to mAbs 6F5, 7C8 and 12H5.

Establishment of double antibodies sandwich ELISA (DAS-ELISA) for rapid detection of S. eriocheiris. Antigen preparation. Whole-cell S. eriocheiris was used in the following establishment of DAS-ELISA. $100 \mu \mathrm{L}$ S. eriocheiris of $32 \mu \mathrm{g} / \mathrm{mL}$ was used as the positive control, and PBS as the negative control according to the indirect ELISA previously established.

Determination of the best working concentration. A checkerboard titration was applied to investigate the best working concentration of the coating polyclonal $\mathrm{Ab}$ and horseradish peroxidase conjugated $S$. eriocheiris specific mAb 6H7 (HRP-6H7). Results showed that the relatively high $\mathrm{P} / \mathrm{N}$ value can be obtained when the concentration of the coating pAb was $1 \mu \mathrm{g} / \mathrm{mL}$ or $0.5 \mu \mathrm{g} / \mathrm{mL}$ (Table 2). To avoid excessive use of the $\mathrm{pAb}$, the latter concentration was used in the following experiments. For HRP-6H7, the maximum OD value (about $0.5-0.6$ ) was obtained when the concentration of $\mathrm{HRP}-6 \mathrm{H} 7$ was $0.2 \mu \mathrm{g} / \mathrm{mL}$, and the OD value decreased with the reduction of its concentration (Table 2). So $0.5 \mu \mathrm{g} / \mathrm{mL}$ pAb and higher concentration of HRP-6H7 $(2 \mu \mathrm{g} /$ $\mathrm{mL}, 0.4 \mu \mathrm{g} / \mathrm{mL}$ and $0.2 \mu \mathrm{g} / \mathrm{mL}$ ) were used to investigate the best working concentration of HRP-6H7. As shown in Table 3, when the concentration of HRP- $6 \mathrm{H} 7$ was $2 \mu \mathrm{g} / \mathrm{mL}$, the maximum P/N (15.4) value can be obtained, the $\mathrm{OD}$ value of the positive control was nearly 1 , and that of the negative control was less than 0.1 . From the above results, the best working concentration was $0.5 \mu \mathrm{g} / \mathrm{mL}$ for PcAb, and $2 \mu \mathrm{g} / \mathrm{mL}$ for enzyme labelled $\mathrm{mAb}$.

Determination of sensitivity, specificity and repeatability of the DAS-ELISA. To determine the sensitivity of the DAS-ELISA, the concentration of S. eriocheiris was examined using 4-fold serial dilutions $(512 \mu \mathrm{g} / \mathrm{mL}$, $128 \mu \mathrm{g} / \mathrm{mL}, 32 \mu \mathrm{g} / \mathrm{mL}, 8 \mu \mathrm{g} / \mathrm{mL}, 2 \mu \mathrm{g} / \mathrm{mL}, 0.5 \mu \mathrm{g} / \mathrm{mL}, 0.125 \mu \mathrm{g} / \mathrm{mL}, 0.031 \mu \mathrm{g} / \mathrm{mL}, 0.0078 \mu \mathrm{g} / \mathrm{mL}, 0.002 \mu \mathrm{g} / \mathrm{mL})$. As depicted in Fig. $4 \mathrm{a}$, a minimal detection limit of $0.125 \mu \mathrm{g} / \mathrm{mL}(\mathrm{OD} 450 \mathrm{~nm}=0.289)$ was obtained according to the cut-off value $(\mathrm{P} / \mathrm{N}>2.1)$. 


\begin{tabular}{|c|c|c|c|c|c|c|c|c|c|}
\hline & & & & & concen & tion of the PcAb & $\mathrm{g} / \mathrm{mL})$ & & \\
\hline & & & 6 & 4 & 2 & 1 & 0.5 & 0.25 & 0.125 \\
\hline & \begin{tabular}{|l|}
0.2 \\
\end{tabular} & $\mathrm{P}$ & $0.61 \pm 0.014$ & $0.548 \pm 0.006$ & $0.567 \pm 0.005$ & $0.541 \pm 0.007$ & $0.561 \pm 0.01$ & $0.541 \pm 0.007$ & $0.507 \pm 0.007$ \\
\hline & & $\mathrm{N}$ & $0.071 \pm 0.007$ & $0.058 \pm 0.004$ & $0.047 \pm 0.005$ & $0.036 \pm 0.004$ & $0.036 \pm 0.04$ & $0.038 \pm 0.006$ & $0.035 \pm 0.003$ \\
\hline & \begin{tabular}{|l|}
0.1 \\
\end{tabular} & $\mathrm{P}$ & $0.483 \pm 0.008$ & $0.445 \pm 0.007$ & $0.401 \pm 0.006$ & $0.395 \pm 0.005$ & $0.434 \pm 0.06$ & $0.409 \pm 0.01$ & $0.405 \pm 0.005$ \\
\hline & & $\mathrm{N}$ & $0.037 \pm 0.003$ & $0.031 \pm 0.003$ & $0.038 \pm 0.004$ & $0.018 \pm 0.002$ & $0.022 \pm 0.006$ & $0.023 \pm 0.002$ & $0.021 \pm 0.008$ \\
\hline & & $\mathrm{N}$ & $0.03 \pm 0.005$ & $0.029 \pm 0.003$ & $0.031 \pm 0.003$ & $0.03 \pm 0.006$ & $0.028 \pm 0.005$ & $0.031 \pm 0.006$ & $0.023 \pm 0.009$ \\
\hline & & PN & 12.4 & 11.7 & 11.2 & 12 & 12.8 & 11 & 14.3 \\
\hline & \begin{tabular}{|l|}
0.05 \\
\end{tabular} & $\mathrm{P}$ & $0.287 \pm 0.004$ & $0.281 \pm 0.005$ & $0.311 \pm 0.003$ & $0.317 \pm 0.004$ & $0.296 \pm 0.008$ & $0.285 \pm 0.006$ & $0.284 \pm 0.013$ \\
\hline & & $\mathrm{N}$ & $0.03 \pm 0.003$ & $0.027 \pm 0.008$ & $0.027 \pm 0.003$ & $0.023 \pm 0.003$ & $0.027 \pm 0.005$ & $0.019 \pm 0.006$ & $0.015 \pm 0.005$ \\
\hline & & PN & 9.6 & 10.4 & 11.5 & 13.8 & 10.9 & 15 & 19 \\
\hline
\end{tabular}

Table 2. Determination for optimal concentration of the coating PcAb and the detecting HRP-McAb. "P": the OD value of the positive control which was read at $450 \mathrm{~nm}$. "N": the OD value of the negative control which was read at $450 \mathrm{~nm}$. "P/N": the ratio of the $\mathrm{OD}$ value of the positive to the value of the negative.

\begin{tabular}{|c|c|c|c|}
\hline \multicolumn{4}{|c|}{ concentration of the PcAb $(0.5 \mu \mathrm{g} / \mathrm{mL})$} \\
\hline \multirow{5}{*}{ concentration of HRP-6H7 $(\mu \mathrm{g} / \mathrm{mL})$} & 2 & $\mathrm{P}$ & $0.998 \pm 0.02$ \\
\cline { 2 - 4 } & & $\mathrm{N}$ & $0.065 \pm 0.007$ \\
\cline { 2 - 4 } & & $\mathrm{P} / \mathrm{N}$ & 15.4 \\
\cline { 2 - 4 } & 0.4 & $\mathrm{P}$ & $0.663 \pm 0.05$ \\
\cline { 2 - 4 } & & $\mathrm{N}$ & $0.047 \pm 0.004$ \\
\cline { 2 - 4 } & & $\mathrm{P} / \mathrm{N}$ & 14.1 \\
\cline { 2 - 4 } & 0.2 & $\mathrm{P}$ & $0.458 \pm 0.04$ \\
\cline { 2 - 4 } & & $\mathrm{N}$ & $0.052 \pm 0.005$ \\
\cline { 2 - 4 } & & $\mathrm{P} / \mathrm{N}$ & 8.8 \\
\hline
\end{tabular}

Table 3. Determination for optimal concentration of the detecting HRP-McAb. "P": the OD value of the positive control which was read at $450 \mathrm{~nm}$. "N": the OD value of the negative control which was read at $450 \mathrm{~nm}$. "P/N": the ratio of the OD value of the positive to the value of the negative.

a

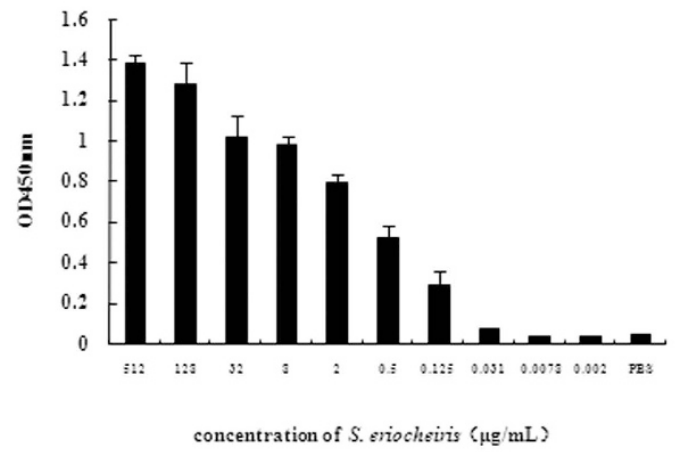

$\mathrm{b}$

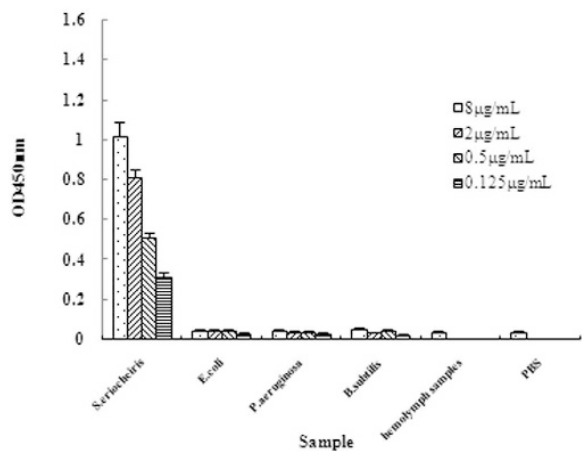

Figure 4. (a) Analytical sensitivity of the DAS-ELISA. The abscissa was the concentration of S. eriocheiris and ordinal coordinates was OD values. The original antigen protein content was $512 \mu \mathrm{g} / \mathrm{mL}$. The lowest concentration that $S$. eriocheiris could be detected by the DAS-ELISA was $0.125 \mu \mathrm{g} / \mathrm{mL}$. (b) Specificity of the DAS-ELISA. Hemolymph samples obtained from healthy, uninfected crabs and PBS were used as a negative control.

Three different bacterial species (B. subtilis, P. aeruginosa, E. coli) which are commonly found in aquaculture were employed to identify the cross-reactivity of the DAS-ELISA. No significant cross-reactivity was detected according to the results. The OD450 values of the 3 bacterial species were similar to that of hemolymph samples obtained from healthy, uninfected crabs and PBS, which indicated the DAS-ELISA method has a high specificity for S. eriocheiris (Fig. 4b). 


\begin{tabular}{|c|c|c|c|c|c|c|c|}
\hline \multirow{2}{*}{$\begin{array}{l}\text { Concentration of } \\
\text { S.eriocheiris }(\mu \mathrm{g} / \mathrm{mL})\end{array}$} & \multirow[b]{2}{*}{ No. } & & \multirow[b]{2}{*}{ OD value } & & \multicolumn{3}{|c|}{ Within plate } \\
\hline & & & & & Mean & SD & C V(\%) \\
\hline \multirow{4}{*}{8} & I & 0.972 & 0.864 & 0.924 & 0.92 & 0.054 & 0.059 \\
\hline & II & 0.875 & 0.936 & 0.952 & 0.921 & 0.041 & 0.044 \\
\hline & III & 0.895 & 0.872 & 0.898 & 0.888 & 0.014 & 0.016 \\
\hline & IV & 0.94 & 0.883 & 0.879 & 0.901 & 0.034 & 0.038 \\
\hline \multirow{4}{*}{2} & I & 0.813 & 0.746 & 0.808 & 0.789 & 0.037 & 0.047 \\
\hline & II & 0.825 & 0.698 & 0.791 & 0.771 & 0.066 & 0.085 \\
\hline & III & 0.764 & 0.711 & 0.634 & 0.703 & 0.065 & 0.093 \\
\hline & IV & 0.779 & 0.814 & 0.701 & 0.765 & 0.058 & 0.076 \\
\hline \multirow{4}{*}{0.5} & I & 0.536 & 0.55 & 0.467 & 0.518 & 0.044 & 0.086 \\
\hline & II & 0.584 & 0.574 & 0.506 & 0.555 & 0.042 & 0.077 \\
\hline & III & 0.535 & 0.516 & 0.473 & 0.508 & 0.032 & 0.063 \\
\hline & IV & 0.487 & 0.524 & 0.589 & 0.533 & 0.052 & 0.097 \\
\hline
\end{tabular}

Table 4. Intra-plate coefficient of variation of the DAS-ELISA for S. eriocheiris. "S D": Standard deviation. "C V": Coefficient of variation. "No.": Plate number.

\begin{tabular}{|l|c|c|c|c|c|c|c|}
\hline \multirow{2}{*}{$\begin{array}{l}\text { Concentration of } \\
\text { S.eriocheiris }(\boldsymbol{\mu} \mathbf{g} / \mathbf{m L})\end{array}$} & \multicolumn{4}{|c|}{$\begin{array}{c}\text { Mean of the OD value of different } \\
\text { plates }\end{array}$} & \multicolumn{4}{c|}{ Between plates } \\
\cline { 2 - 9 } & I & II & III & IV & Mean & S D & C V $(\%)$ \\
\hline 8 & 0.92 & 0.9 & 0.888 & 0.901 & 0.908 & 0.016 & 0.017 \\
\hline 2 & 0.789 & 0.8 & 0.703 & 0.765 & 0.757 & 0.037 & 0.049 \\
\hline 0.5 & 0.518 & 0.6 & 0.508 & 0.533 & 0.528 & 0.02 & 0.039 \\
\hline
\end{tabular}

Table 5. Inter-plate coefficient of variation of the DAS-ELISA for S. eriocheiris. "S D": Standard deviation. "C V": Coefficient of variation.

Three different concentrations $(8 \mu \mathrm{g} / \mathrm{mL}, 2 \mu \mathrm{g} / \mathrm{mL}$ and $0.5 \mu \mathrm{g} / \mathrm{mL})$ of S. eriocheiris were used to calculate the intra- and inter-plate coefficient of variation (CV). CV of the intra-plate and inter-plate were both lower than $10 \%$ (Table 4 and Table 5), which is within the expected range of ELISA. The intra- and inter-plate coefficient of variations were used to validate the repeatability of the DAS-ELISA. These results indicated that the DAS-ELISA we developed offered high repeatability.

\section{Discussion}

Spiroplasma diseases are most often found in association with insects and plants ${ }^{3}$. However, one species within this group, S. eriocheiris, was isolated from several freshwater aquatic crustaceans including E. sinensis, L. vannamei, P. clarkii, M. rosenbergii and M. nipponense $e^{1,2}$.

This spiroplasma is of additional interest because of its well-established role as a pathogen of freshwater aquatic crustaceans, and is of significant economic importance ${ }^{1}$. As a new isolated and important pathogen, elucidation of the molecular characteristics and development of a rapid, convenient detection method are urgently needed.

Antibodies are important tools for the study of the characteristics, pathogenesis, rapid detection methods, prevention and treatment of pathogens ${ }^{11}$. A polyclonal antibody against S. eriocheiris was developed soon after the spiroplasma was identified. It was used in the indirect ELISA to detect S. eriocheiris in crab hemolymph ${ }^{8}$. It is known that $m A$ bs have significant advantages over polyclonal counterparts in the epitope analysis and differentiation of pathogens because of their binding with high specificity and high affinity to a target molecule. Developing $\mathrm{mAbs}$ should be very important because $\mathrm{mAbs}$ specific to $S$. eriocheiris will be a useful tool in the study of antigenic epitopes of $S$. eriocheiris proteins and epidemiological survey of TD. To date, only one $\mathrm{mAb} 6 \mathrm{H} 7$ has been produced $^{7}$. Catastrophic economic losses caused by outbreaks of TD enabled the production of more mAbs and pAbs described in the present study. In this study we prepared $5 \mathrm{mAbs}$ and a pAb against $S$. eriocheiris by immunizing mice or rabbits with $S$. eriocheiris.

Among the five mAbs, 7C8 reacted specifically to S. eriocheiris as shown by ELISA and Western blotting, but not to other microbes we tested. It suggests that the epitope detected by this $\mathrm{mAb}$ is highly specific to the newly defined spiroplasma, just like the first mAb $6 \mathrm{H} 7$ we produced. To date, many specific mAbs have been used in the establishment of immunological assays for the detection of pathogenic microbial antigens ${ }^{12-14}$. These $2 \mathrm{mAbs}$ can therefore be used to distinguish S. eriocheiris from other spiroplasmas.

Diagnosis of $S$. eriocheiris infection is essential for the treatment of tremor disease. Presently, some methods requiring special equipment and expensive reagents, such as light microscopy, electron microscopy and PCR-based molecular techniques, have been used for identification of $S$. eriocheiris from crustaceans and other aquatic ani$\mathrm{mals}^{8}$. ELISA is more suitable for field applications in aquaculture farms because of its simplicity, inexpensiveness, and reliability; and there have been a few reports of ELISA detection for spiroplasmas from plants and insects tissues ${ }^{15-17}$. Indirect ELISA was established using the polyclonal antibody against S. eriocheiris ${ }^{8}$. Among various ELISA formats, DAS-ELISA is most commonly used and time-saving in the detection of the pathogen. 
And a series of mAbs and pAb we produced also offered a wider choice of reagents for the establishment of this method. The surface proteins are the most appropriate target for the diagnosis of pathogen infection. We have two S. eriocheiris specific mAbs (7C8 and 6H7) which can be used to develop the DAS-ELISA. There are two reasons for why the latter was chosen as an agent for the establishment of the assay. Firstly, $6 \mathrm{H} 7 \mathrm{had}$ higher affinity to S. eriocheiris than 7C8. Secondly, one of our goals to develop mAbs against S. eriocheiris is to establish a convenient and efficient method to detect viable $S$. eriocheiris cells; therefore, the sensitivity and reliability of this method is critical to achieve this goal. MAb $6 \mathrm{H} 7$ proved to have high binding affinity to ALP41, which is an important and constitutional expressed surface protein of $S$. eriocheiris. To improve the sensitivity, pAb combined with more epitopes was coated to capture more relevant antigens. The minimal detection limit is lower than that of the indirect ELISA established previously, which indicated that DAS-ELISA may offer higher sensitivity. This seemed attractive in detecting subclinical infections. It is noteworthy that no background was observed in the hemolymph specimens which were examined by the protocol described herein. So DAS-ELISA was proven useful for detecting S. eriocheiris antigens in clinical samples.

In the cell-wall-free mollicutes, membrane molecules are of primary importance in adherence, invasion, shape determination, and interaction with the host immune system. And they may also display structural, transport, or enzymic functions ${ }^{18,19}$. MAbs $6 \mathrm{~F} 5,7 \mathrm{C} 8$ and $12 \mathrm{H} 5$ we produced were able to deform $20 \%$ to $30 \%$ of S. eriocheiris. The $3 \mathrm{mAbs}$ may interact with epitopes of shape determination-associated proteins or an epitope shared by various proteins functionally related to shape determination. Thus, we identified the binding motif of the mAbs via a phage display library (Ph.D.-12).

The sequence (YMRDMQSGLPRY) containing a binding site to the mAbs was highly homologous to amino acid sequence 242-253 of Mreb1 and MreB4 (cell shape determining protein) from S. eriocheiris and S. mirum. MreB is the bacterial homologue of eukaryotic actin. MreB genes are present only in bacterial species with rod-shaped, filamentous, or helical cells ${ }^{20}$. Its major function appears to be the control of cell shape, mainly by directing cell wall building blocks to their destination ${ }^{21}$. Since Spiroplasma lacks a cell wall, MreB's function is different from that in E. coli. It has been identified in $S$. citri and $S$. melliferum which is a protein about $36 \mathrm{kDa}^{21,22}$. And it is likely that it forms a membrane-associated helical ribbon, and then a highly ordered linear motor positioned on a defined helical line along the internal face of the cell's membrane. There are five mreB homologs in the draft genome sequences of these two spiroplasmas, encoding MreB proteins with a molecular weight of $38 \mathrm{kDa}$ (unpublished data). The functional roles of these MreB homologs remain to be investigated ${ }^{23}$. We assume that the mAbs deformed S. eriocheiris by binding the motifs of MreBs or other proteins with the same conformational epitope, triggering mechanical forces responsible for the loss of helicity. As a component of the cytoskeleton, MreB is firmly attached to the cytoplasmic face of the membrane. Although the studies suggested that the mAbs were likely interacting with MreB, how and where this interaction was occurring remained a mystery. It is possible that MreB may span the plasma membrane, leaving a small region exposed outside of the cell while another terminus is located on the cytosolic side under some conditions just like HSP72 $24-26$.

S. eriocheiris and S. mirum are $98.8 \%$ identical at the nucleotide sequence level in MreB1, 97.9\% in MreB4. The molecular basis of antigen-antibody interaction is that the CDR (complementarity-determining region) of $\mathrm{Ab}$ binds to the small region of a large antigen which is called the antigenic epitope. Studies of many Ag-Ab interfaces have revealed that the contact residues of antigenic epitope are often discontinuous in sequence but contiguous in space. That means the antibody recognizes the overall shape of an epitope rather than particular chemical residues. Ag-Ab reactions can show a high level of specificity. Ab is able to distinguish between small differences in the primary amino acid sequence of proteins, in addition to differences in charge, optical configuration and steric conformation. The single amino acid mutations in the protein, although fairly distant from the contact residues, appeared to induce subtle conformational changes leading to the changes of the interaction with antibody ${ }^{27,28}$. Therefore, it is proposed that few different amino acids of MreB1/4 at S. eriocheiris and S. mirum alter the partial conformation of the proteins, thereby forming common and specific motifs of MreB1/4 between S. eriocheiris and S. mirum. MAb 7C8 may bind S. eriocheiris specific motifs of MreB1/4, while mAbs $6 \mathrm{~F} 5$ and $12 \mathrm{H} 5$ bind common ones of them, consistent with the results before (Fig. 1a,b). As the peptide displayed on the surface of the phage presents a primary conformation, 7C8 showed significantly lower signals in the phage ELISA binding assay than the other two mAbs (Fig. 3c,d).

In conclusion, we generated and characterized $5 \mathrm{mAbs}$ directed against $S$. eriocheiris. The epitopes of $S$. eriocheiris detected by $7 \mathrm{C} 8$ are quite different from that by the other four $\mathrm{mAbs}$; therefore, the mAbs may have different biological effects. In addition, these mAbs could offer new approaches for the study of S. eriocheiris. Used as ligands, they could enable the isolation and purification of $S$. eriocheiris proteins utilizing methods such as affinity chromatography or immunomagnetic separation. A specific motif (FQGINHYNQMER) of cell shape determining protein (Mreb) of $S$. eriocheiris was identified from a phage display peptide library by using $m$ Abs $6 \mathrm{~F} 5,7 \mathrm{C} 8$ or $12 \mathrm{H} 5$ which deformed $S$. eriocheiris as baits. This motif and the $3 \mathrm{mAbs}$ can be used as biological tools in further research on the role of MreB of S. eriocheiris in both the physiology and pathogenesis. As a result of our research, a DAS-ELISA for the detection of the pathogen was established, using rabbit anti-S. eriocheiris serum as a coating antibody, HRP-labelled $6 \mathrm{H} 7$ as the detecting antibody, and finally an optimized protocol was developed. It was sensitive and specific for S. eriocheiris detection, simple and time-saving to produce and perform compared to existing serological methods. Our results indicated that the DAS-ELISA is a suitable method for the diagnosis of $S$. eriocheiris infection and could be used in serological surveys to map out the prevalence of TD.

\section{Methods}

Ethics statement. All experimental protocols were approved by the ethics committee of the Medical School of Southeast University, Nanjing, Jiangsu. The methods were carried out in accordance with the approved guidelines. All animal experiments were conducted in accordance with the protocols evaluated and approved by 
Institutional Animal Care and Use Committee (IACUC) of the Medical School of Southeast University (approval ID: SYXK-2010.4987).

Bacterial strains. Spiroplasma mirum was purchased from the American Type Culture Collection (ATCC 29335). S. eriocheiris was isolated from E. sinensis that were exhibiting the tremor disease using a previously described method ${ }^{1}$.

Preparation of immunogen and production of mAbs. Whole-cell S. eriocheiris and S. eriocheiris cells broken by ultrasonic homogenizer were used as antigens ${ }^{7}$. MAbs were produced using the standard procedures described previously ${ }^{7,29,30}$. The ascites containing mAbs were collected and purified with protein A/G affinity columns (Millipore, USA). The concentration of the mAb was determined with the BCATM Protein Assay Kit (Thermo, USA). The established hybridoma cell lines were stored in liquid nitrogen for later use. The Ig isotype of the mAb was identified using the IsoStrip Mouse Monoclonal Antibody Isotyping Kit (Roche, Germany) according to the manufacturer's instructions.

Rabbit immunization and pAb preparation. The Poly Ab was generated by immunizing the New Zealand white rabbits with bacteria as previously described with some modification ${ }^{31}$. Briefly, rabbits were immunized with $6 \times 10^{8} \mathrm{~S}$. eriocheiris cells by hypodermic injection with equal volumes of Freund's complete adjuvant. The immunization was repeated at days $21,35,49$ and 63 after the first injection with Freund's incomplete adjuvant. The animals were bled one week after the fifth injection and the sera were collected by centrifuging clotted blood at $2,000 \mathrm{~g}$ and stored at $-20^{\circ} \mathrm{C}$. Preimmunization sera were obtained and used as a control. All antisera were heat-inactivated at $56^{\circ} \mathrm{C}$ for $30 \mathrm{~min}$ and filtered through $450-\mathrm{nm}$ membrane filters. The sera were purified with protein A/G affinity columns (Millipore, USA). The concentration of the pAb was determined with the BCATM Protein Assay Kit (Thermo, USA).

Indirect ELISA. Indirect ELISA for screening anti-S. eriocheiris hybridoma, measuring titrations of S. eriocheiris antibodies in affinity-purified ascites or rabbit serum and testing the specificities of the Abs to other species of spiroplasmas or Ureaplasma urealyticum were done as we previously described ${ }^{7}$. The end point dilution method was used to determine the titer of antibodies by the indirect ELISA. Antibody titers were defined as the reciprocal of the highest ascites or serum dilution that produced an O.D value above the cutoff 7 . The experiment was repeated 3 times, and the results are presented as mean $\pm S D$.

The affinity constant (Kaff) of $\mathrm{mAb}$ for binding to S. eriocheiris. The affinity constant of the mAb was determined as we described before ${ }^{7,32}$.

Western blot assay for testing the specificities of the affinity-purified mAbs or pAb to other species of spiroplasmas or Ureaplasma urealyticum. Standard procedures of Western blotting were used to determine the reactivity of the $\mathrm{mAb}$ or pAb to the whole cell lysates of S. eriocheiris, $S$. melliferum, $S$. mirum and $U$. urealyticum on a $12 \%$ gel $^{7}$. The $\mathrm{mAbs}$ or pAb we prepared were used as the primary antibody and the HRP conjugated goat anti-mouse IgG Fc or anti-rabbit as the secondary antibody (Chemicon, Japan). The culture medium of spiroplasmas or pre-immunized rabbit serum was used as the negative control.

Western blot assay for testing the reactivities of the mAbs to the S. eriocheiris strains from eight different areas in Jiangsu province. The procedure was similar to that described above.

\section{Effects of mAbs on the biological characeristics of S. eriocheiris.}

Deformation test. Deformation test was done according to the method reported before with slight modifications ${ }^{33}$. Briefly, $50 \mu \mathrm{lmAbs}$ to be examined were added to the same volume of $S$. eriocheiris cultures in the logarithmic phase of growth. S. eriocheiris cultures were used as a control. The treated samples were incubated at room temperature for thirty minutes and then examined using dark-field microscopy. The control was read first.

Growth inhibition test. Samples $(0.1 \mathrm{~mL})$ of S. eriocheiris cultures in the logarithmic phase of growth were plated onto plate agar surfaces consisting of sucrose and indicator-Phenol red. Thirty minutes later, the sterile disks saturated with $\mathrm{mAbs}$ were placed on the surface of the agar at the center of the dried inoculated plates. The plates were then incubated in $30^{\circ} \mathrm{C}$ incubator. The sterile disk saturated with $\mathrm{R} 2$ medium was used as a negative control.

Metabolism inhibition test. Two fold dilutions of Abs and tenfold dilutions of S. eriocheiris were made firstly. Two hundred $\mu \mathrm{L}$ of $S$. eriocheiris cultures were added to $50 \mu \mathrm{L}$ mAbs to be examined, then mixed thoroughly. R2 medium, S. eriocheiris culture and Abs served as different controls. All tubes were placed in $30^{\circ} \mathrm{C}$ incubator for 3 to 10 days. When the color of the medium control remained unchanged and S. eriocheiris suspension turned yellow, the highest dilution of $\mathrm{Ab}$ in which the metabolism of S. eriocheiris were inhibited was recorded.

Screening the phage display library using the mAbs which have effects on the biological characeristics of $S$. eriocheiris as the target molecule and sequencing DNA. Ph.D.-12 Phage Display Peptide Library (New England Biolabs, USA) was used in this study. Four rounds of biopanning were undertaken according to the manufacturer's instructions to investigate the binding motif of mAbs which have effects on the biological characeristics of $S$. eriocheiris. After the fourth round of panning, 48 individual blue plaques were picked from LB/IPTG/X-gal plates randomly. They were cloned and amplified. The inserted DNA was sequenced 
and translated into peptides. Homology searches and multiple sequence alignments were performed using DNA Star and Clustal W programs to determine the similarities between the consensus peptides of S. eriocheiris and S. mirum.

Phage ELISA binding assay. To test the binding specificities of the selected phage clones, phage ELISA binding assay was performed by coating one row of ELISA plate with mAbs for each phage clone. The amounts of recombinant phages bound to the mAbs were determined using HRP-conjugated anti-M13 antibody. All phage clones were tested in triplicate, and the results are presented as mean $\pm \mathrm{SD}$.

\section{Establishment of double antibody sandwich ELISA.}

Preparation of antigens. Whole-cell S. eriocheiris were used as antigens in the DAS-ELISA. Other aquaculture-associated bacterial isolates (Bacillus subtilis, Pseudomonas aeruginosa and Escherichia coli,) were obtained by courtesy of Southeast University, Department of Pathogenic Biology and Immunology. Ultrasonic fragmentation of the agents were used as control antigens.

Conjugation of mAb to horseradish peroxidase. Horseradish peroxidase was conjugated to the S. eriocheiris specific mAb 6H7 with Peroxidase Labeling Kit according to the manufacturer's instructions (Roche Ltd).

Development of DAS-ELISA. Microplates (MaxiSorp, Nunc) were coated with anti-S. eriocheiris rabbit serum of the optimized working concentration (in $0.05 \mathrm{M}$ carbonate buffer, $\mathrm{pH} 9.6,100 \mu \mathrm{L} /$ well) overnight at $4^{\circ} \mathrm{C}$. A blocking buffer (PBS-T containing $2 \%$ rabbit serum, $200 \mu \mathrm{L} /$ well) was added to the plate for $1 \mathrm{~h}$ at $37^{\circ} \mathrm{C}$ followed by thrice washing with PBS-T. After the plate was washed as described above, the sample (diluted with rabbit serum containing PBS) was added and the plate was incubated at $37^{\circ} \mathrm{C}$ for $1 \mathrm{~h}$. S. eriocheiris of known concentrations $(32 \mu \mathrm{g} / \mathrm{mL}, 100 \mu \mathrm{L} /$ well $)$ was used as positive control according to the previous study and PBS as negative control. Positive and negative controls were treated in the same way. After washing as before, horseradish peroxidase conjugated $\mathrm{mAb} 6 \mathrm{H} 7(\mathrm{HRP}-6 \mathrm{H} 7)$ was added at the optimized working concentration and incubated once more for $1 \mathrm{~h}$ at $37^{\circ} \mathrm{C}$. The plate was then treated with the tetramethylbenzidine substrate followed by washing 5 times. After incubation in the dark for approximately $10 \mathrm{~min}$, a stopping solution $\left(2 \mathrm{~mol} / \mathrm{l} \mathrm{H}_{2} \mathrm{SO}_{4}, 50 \mu \mathrm{L} /\right.$ well) was added. The absorption was measured at $450 \mathrm{~nm}$ using a microplate reader. The experiment was repeated three times, and the results are presented by mean $\pm \mathrm{SD}$.

Optimization of working concentration. To develop a highly sensitive and specific DAS-ELISA, assay conditions were optimized according to the checkerboard titration method ${ }^{34}$, including the concentration of coating anti-S. eriocheiris rabbit serum and HRP-6H7. The optimized working concentration of coating pAb and HRP-6H7 were determined via the ratio of the OD value of the positive to the value of the negative $(\mathrm{P} / \mathrm{N})$.

\section{Determination of sensitivity, specificity and repeatability of the DAS-ELISA.}

Sensitivity of the DAS-ELISA. Different concentrations of S. eriocheiris $(512 \mu \mathrm{g} / \mathrm{mL}, 128 \mu \mathrm{g} / \mathrm{mL}, 32 \mu \mathrm{g} / \mathrm{mL}, 8 \mu \mathrm{g} /$ $\mathrm{mL}, 2 \mu \mathrm{g} / \mathrm{mL}, 0.5 \mu \mathrm{g} / \mathrm{mL}, 0.125 \mu \mathrm{g} / \mathrm{mL}, 0.031 \mu \mathrm{g} / \mathrm{mL}, 0.0078 \mu \mathrm{g} / \mathrm{mL}, 0.002 \mu \mathrm{g} / \mathrm{mL}$ ) were examined to determine the lowest concentration of antigen based on the working concentration of $\mathrm{pAb}$ and HRP-6H7. The values of P/N larger than 2.1 were considered as positive.

Cross-reactivity Assessment of the DAS-ELISA. B. subtilis, P. aeruginosa, E. coli and hemolymph samples obtained from healthy, uninfected crabs and sterile PBS were tested against the DAS-ELISA we developed. $S$. eriocheiris were used as positive control and PBS as negative control.

Repeatability of the DAS-ELISA. The DAS-ELISA we developed was used to assess S. eriocheiris of 3 different concentrations $(8 \mu \mathrm{g} / \mathrm{mL}, 2 \mu \mathrm{g} / \mathrm{mL}$ and $0.5 \mu \mathrm{g} / \mathrm{mL})$ with four microplates to calculate the variation. Each concentration of $S$. eriocheiris were tested in three replicates within any of the four microplates. The coefficients of variation $(\mathrm{CV}=\mathrm{SD} /$ Mean $\times 100 \%)$ were calculated and the intra-plate variation and inter-plate variation were used to validate the repeatability of the DAS-ELISA ${ }^{35}$.

\section{References}

1. Wang, W. et al. Spiroplasma eriocheiris sp. nov., associated with mortality in the Chinese mitten crab, Eriocheir sinensis. International journal of systematic and evolutionary microbiology. 61, 703-708 (2011).

2. Xiu, Y. J., Wu, T., Meng, X. H., Meng, Q. G. \& Wang, W. Identification and isolation of a spiroplasma pathogen from diseased oriental river prawn, Macrobrachium nipponense, in China: A new freshwater crustacean host. Aquaculture. 437, 270-274 (2015).

3. Regassa, L. B. \& Gasparich, G. E. Spiroplasmas: evolutionary relationships and biodiversity. Frontiers in bioscience: a journal and virtual library. 11, 2983-3002 (2006).

4. Meng, Q., Gu, W., Bi, K., Ji, H. \& Wang, W. Spiralin-like protein SLP31 from Spiroplasma eriocheiris as a potential antigen for immunodiagnostics of tremor disease in Chinese mitten crab Eriocheir sinensis. Folia microbiologica. 55, 245-250 (2010).

5. Meng, Q. et al. Identification of adhesin-like protein ALP41 from Spiroplasma eriocheiris and induction immune response of Eriocheir sinensis. Fish \& shellfish immunology. 29, 587-593 (2010).

6. Meng, Q. et al. Identification and characterization of spiralin-like protein SLP25 from Spiroplasma eriocheiris. Veterinary microbiology. 144, 473-477 (2010).

7. Zhang, Y. et al. Characterization of a monoclonal antibody to Spiroplasma eriocheiris and identification of a motif expressed by the pathogen. Veterinary microbiology. 161, 353-358 (2013).

8. Wang, J. et al. Enzyme-liked immunosorbent assay for the detection of pathogenic spiroplasma in commercially exploited crustaceans from China. Aquaculture. 292, 166-171 (2009).

9. Kolonin, M. G. et al. Synchronous selection of homing peptides for multiple tissues by in vivo phage display. The FASEB Journal. 20, 979-981 (2006).

10. Mullen, L. M., Nair, S. P., Ward, J. M., Rycroft, A. N. \& Henderson. B. Phage display in the study of infectious diseases. Trends in microbiology. 14, 141-147 (2006). 
11. Irving, J. A. et al. An antibody raised against a pathogenic serpin variant induces mutant-like behaviour in the wild-type protein. The Biochemical journal. 468, 99-108 (2015)

12. Coetzer, A., Sabeta, C. T., Markotter, W., Rupprecht, C. E. \& Nel, L. H. Comparison of biotinylated monoclonal and polyclonal antibodies in an evaluation of a direct rapid immunohistochemical test for the routine diagnosis of rabies in southern Africa. PLoS neglected tropical diseases. 8, e3189 (2014).

13. Okuda, M. et al. Evaluation of a stool antigen test using a $\mathrm{mAb}$ for native catalase for diagnosis of Helicobacter pylori infection in children and adults. Journal of medical microbiology. 63, 1621-1625 (2014).

14. Wang, Q. et al. Development and evaluation of a competitive ELISA using a monoclonal antibody for antibody detection after goose parvovirus virus-like particles (VLPs) and vaccine immunization in goose sera. Journal of virological methods. 209, 69-75 (2014).

15. Bove, J. M., Fos, A. \& Lallemand, J. Epidemiology of Spiroplasma citri in the Old World. Israel journal of medical sciences. 23, 663-666 (1987).

16. Bove, J. M., Vignault, J. C. \& Saillard, C. Spiroplasma citri detection by enzyme-linked immunosorbent assay (ELISA), culture and dot hybridization. Israel journal of medical sciences. 23, 729-731 (1987).

17. Carloni, E. et al. Exitianus obscurinervis (Hemiptera: Cicadellidae), a new experimental vector of Spiroplasma kunkelii. Journal of economic entomology. 104, 1793-1799 (2011).

18. Chambaud, I., Wroblewski, H. \& Blanchard, A. Interactions between mycoplasma lipoproteins and the host immune system. Trends in microbiology. 7, 493-499 (1999).

19. Razin, S., Yogev, D. \& Naot, Y. Molecular biology and pathogenicity of mycoplasmas. Microbiology and molecular biology reviews : MMBR. 62, 1094-1156 (1998).

20. Kurner, J., Frangakis, A. S. \& Baumeister, W. Cryo-electron tomography reveals the cytoskeletal structure of Spiroplasma melliferum. Science. 307, 436-438 (2005).

21. Trachtenberg, S. et al. Structure of the cytoskeleton of Spiroplasma melliferum BC3 and its interactions with the cell membrane. Journal of molecular biology. 378, 778-789 (2008).

22. Trachtenberg, S., Schuck, P., Phillips, T. M., Andrews, S. B. \& Leapman, R. D. A structural framework for a near-minimal form of life: mass and compositional analysis of the helical mollicute Spiroplasma melliferum BC3. PloS one. 9, e87921 (2014).

23. Ku, C., Lo, W. S. \& Kuo, C. H. Molecular evolution of the actin-like MreB protein gene family in wall-less bacteria. Biochemical and biophysical research communications. 446, 927-932 (2014).

24. Vega, V. L. et al. Hsp70 translocates into the plasma membrane after stress and is released into the extracellular environment in a membrane-associated form that activates macrophages. Journal of immunology. 180, 4299-4307 (2008).

25. Agulla, J. et al. In vivo theranostics at the peri-infarct region in cerebral ischemia. Theranostics. 4, 90-105 (2013).

26. Gupta, A. et al. Toll-like receptor agonists and febrile range hyperthermia synergize to induce heat shock protein 70 expression and extracellular release. The Journal of biological chemistry. 288, 2756-2766 (2013).

27. Peng, L., Oganesyan, V., Wu, H., Dall'Acqua, W. F. \& Damschroder, M. M. Molecular basis for antagonistic activity of anifrolumab, an anti-interferon-alpha receptor 1 antibody. $m A$ bs. 7, 428-439 (2015).

28. Ryman, K. D., Ledger, T. N., Campbell, G. A., Watowich, S. J. \& Barrett, A. D. Mutation in a 17D-204 vaccine substrain-specific envelope protein epitope alters the pathogenesis of yellow fever virus in mice. Virology. 244, 59-65 (1998).

29. Zhang, H., Dai, X., Shan, X. \& Meng, J. Characterization of antigenic epitopes of the ORF2 protein from hepatitis E virus genotype 4. Virus research. 142, 140-143 (2009).

30. Kohler, G. \& Milstein, C. Continuous cultures of fused cells secreting antibody of predefined specificity. Nature. 256, 495-497 (1975).

31. Malembic, S., Saillard, C., Bove, J. M. \& Garnier, M. Effect of polyclonal, monoclonal, and recombinant (single-chain variable fragment) antibodies on in vitro morphology, growth, and metabolism of the phytopathogenic mollicute Spiroplasma citri. Applied and environmental microbiology. 68, 2113-2119 (2002).

32. Beatty, J. D., Beatty, B. G. \& Vlahos, W. G. Measurement of monoclonal antibody affinity by non-competitive enzyme immunoassay. Journal of immunological methods. 100, 173-179 (1987).

33. French, F. E., Whitcomb, R. F., Williamson, D. L. \& Regassa, L. B. Rapid polyvalent screening for largescale environmental Spiroplasma surveys. Brazilian journal of microbiology: [publication of the Brazilian Society for Microbiology]. 40, 663-669 (2009).

34. Zhang, M. et al. A double antibody sandwich enzyme-linked immunosorbent assay for detection of soft-shelled turtle iridovirus antigens. Journal of virological methods. 167, 193-198 (2010).

35. Parreño, V. et al. Development and statistical validation of a guinea pig model for vaccine potency testing against Infectious Bovine Rhinothracheitis (IBR) virus. Vaccine. 28, 2539-2549 (2010).

\section{Acknowledgements}

We gratefully acknowledge Professor O. Roger Anderson from Columbia University in America for editing the manuscript. The current study was supported by the National Basic Research Program of China (973 program, No. 2013CB733801), the Key Project of Jiangsu Province Natural Science Foundation of China (No. BK20130057) and the National Natural Science Foundation of China (No. 81272400).

\section{Author Contributions}

Y.Z. designed and conducted the experiments, interpreted the data and drafted the manuscript. H.B. performed experiments and analyzed data. F.M. helped with the design of the study, collected and analyzed data. Y.P. helped to analyze the similarities between the consensus peptides of S. eriocheiris and S. mirum. Y.S. helped with the design of the experiments. W.G. participated in the deformation test and the analysis of the data. Q.M. helped to analyze data and revise the manuscript. W.W. helped with the design of the experiments and to revise the manuscript. J.Z. designed the experiments and helped to draft the manuscript. All authors reviewed and approved the final manuscript.

\section{Additional Information}

Competing financial interests: The authors declare no competing financial interests.

How to cite this article: Zhang, Y. et al. Production and application of polyclonal and monoclonal antibodies against Spiroplasma eriocheiris. Sci. Rep. 5, 17871; doi: 10.1038/srep17871 (2015).

This work is licensed under a Creative Commons Attribution 4.0 International License. The images or other third party material in this article are included in the article's Creative Commons license, unless indicated otherwise in the credit line; if the material is not included under the Creative Commons license, users will need to obtain permission from the license holder to reproduce the material. To view a copy of this license, visit http://creativecommons.org/licenses/by/4.0/ 